\title{
Vertentes atuais da literatura canadense de língua inglesa e francesa
}

\author{
Current Perspectives on Canadian Literature in English and French
}

\author{
Zilá Bernd \\ Universidade Federal do Rio Grande do Sul - Porto Alegre - Rio Grande do Sul - Brasil \\ Centro Universitário La Salle - Canoas - Rio Grande do Sul - Brasil \\ Ana Maria Lisboa de Mello \\ Pontifícia Universidade Católica do Rio Grande do Sul - Porto Alegre - Rio Grande do Sul - Brasil \\ Eloína Prati dos Santos \\ Universidade Federal do Rio Grande do Sul - Porto Alegre - Rio Grande do Sul - Brasil
}

$\diamond$

\begin{abstract}
Resumo: O artigo focaliza as tendências atuais da Literatura canadense em línguas inglesa e francesa, destacando ainda a forte presença atual da literatura indígena ou aborígene, que se exprime principalmente em língua inglesa. $\mathrm{O}$ artigo salienta a importância no atual contexto literário do Canadá as literaturas chamadas de migrantes ou transnacionais que são as produzidas por autores de diferentes nacionalidades chegados ao Canadá e que, tanto em língua francesa como inglesa, se caracterizam pela hibridação das culturas de origem de seus autores com as culturas do país de chegada.
\end{abstract}

Palavras-chave: Literatura canadense; Migrações; Ameríndios; Hibridismo; Transnacionalidade; Transculturalismo

\begin{abstract}
The article focuses on contemporary trends in Canadian Literature, stressing the strong presence of First Nations writing. It brings out the importance of the so called migrant or transnational literatures, produced by authors from different nationalities living in Canada whose work, in English and in French, is characterized by the hybridization of the culture of origin and that of the receiving country.
\end{abstract}

Keywords: Canadian literature; Migrations; Amerindians; Hybridization Transnationality; Transculturalism

Desde 1991, quando foi fundada a ABECAN Associação Brasileira de Estudos Canadenses-, a literatura canadense vem sendo ensinada em universidades, debatida em colóquios e traduzida para o português, como é o caso dos romances de Nancy Huston, Marcas de Nascença e Dolce Agonia, e do ensaio, Espécie fabuladora, todos publicados pela L\&PM. Contudo, a literatura canadense ainda permanece distante do público leitor brasileiro que, com raras exceções como as que acabamos de citar, só tem acesso a ela no original, em língua inglesa ou francesa.

Essa é a peculiaridade do Canadá: a presença de uma literatura de língua inglesa e, de outra, de língua francesa, que se autodenomina quebequense, pois é originária da província francófona do Quebec. Contudo, falar do bilinguismo canadense, que se revela plenamente em duas expressões literárias distintas, não é suficiente para caracterizá-las, já que o grande contingente de imigrantes que chegam em vagas sucessivas ao Canadá deu origem a uma literatura caracterizada por uma extraordinária diversidade cultural, desconstruindo de algum modo o conceito de identidade nacional. Fala-se hoje, no Canadá, em literaturas migrantes ou transnacionais, pois seus autores escrevem em uma espécie de entre-lugar entre os países de origem e o país de acolhida, o Canadá, dando origem a textos necessariamente híbridos, pois esses escritores buscam representações em dois (ou mais) horizontes culturais.

Trata-se de uma verdadeira poética do Diverso, para utilizarmos a expressão do poeta antilhano Édouard Glissant, que busca compartilhar com seus leitores os 
vestígios memoriais dos países de origem dos imigrantes. Entre esses autores, ditos migrantes, destacam-se, em língua francesa, Dany Laferrière e Marie-Célie Agnant, do Haiti, Sergio Kokis, do Brasil, Ying Chen, da China, Antonio d'Alfonso e Fúlvio Caccia, da Itália, Naïm Kattan, do Iraque, Abla Fahroud, do Líbano, Nadia Ghalem, da Argélia e Andrée Dahan, do Egito, entre muitos outros; e, em língua inglesa, Michael Ondaatje, do Sri Lanka (autor de $O$ paciente inglês, que tem versão para o cinema), Joy Kogawa, do Japão, Dionne Brand, do Caribe, Austin Clarke, de Barbados, Marilú Mallet, do Chile, e Baharati Mukherjwee, de Bengal, na Índia, entre tantos outros. $\mathrm{O}$ grande interesse das produções ficcionais desses autores é justamente o seu caráter transcultural, ou seja, as passagens fertilizadoras de uma cultura a outra engendram produtos culturais novos e originais.

É preciso lembrar que o bilinguismo tem causas históricas: o país foi colonizado primeiramente por franceses, com a chegada de Jacques Cartier à Nouvelle France, hoje província do Quebec, impondo-se a língua francesa, com seus costumes, lendas e também a religião católica. Isto perdura até a invasão inglesa quando, a partir da derrota dos franceses na célebre batalha das Planícies de Abraão, em 1759, a província passa ao domínio inglês. $\mathrm{O}$ que era quase impossível aconteceu: a língua francesa foi preservada, desenvolvendo-se uma imprensa e posteriormente uma literatura em francês, gerando - por um determinado tempo - um anseio de autonomização da província que goza até hoje de um estatuto de "société distincte". O bilinguismo foi oficialmente implantado no Canadá em 1969, sendo que o Multiculturalismo só se tornou política de Estado, a partir de 1971.

Através de versões cinematográficas, algumas obras se tornaram conhecidas no Brasil como a $A$ vida de Pi (Life of $P i$ ), escrita originariamente em inglês e logo traduzida ao francês pelos pais do autor Yann Martel. Após ganhar o famoso Man Booker Prize, no ano de 2002, o livro se torna um best seller, passando para o cinema, em 2012, com a magnífica direção de Ang Lee, que produz As aventuras de Pi, filme que fascinou muitas plateias, inclusive a brasileira. Quem não se lembra da polêmica causada por este livro por apresentar similitudes com a obra de Moacyr Scliar Max e os felinos? Embora sejam ambos calcados no tema de meninos que se salvam de naufrágios em balsas precárias, as obras têm características distintas, tendo ambos em comum a questão da diversidade cultural, a figuração da travessia do Atlântico pelos imigrantes, o impacto da alteridade nos países de chegada e a busca do relacional para harmonizar as diferenças. $\mathrm{O}$ cinema e o teatro ajudaram a aproximar o público brasileiro das obras canadenses como é o caso de Incêndios (Incendies), peça do autor canadense de origem libanesa, Wadji Mouawad, recentemente traduzida e encenada por Aderbal Freire Filho, que apresentou a peça com enorme sucesso em várias capitais, inclusive em Porto Alegre, durante o "Porto Alegre em Cena" 2014.

Se o cinema, o teatro e as traduções estão contribuindo para uma maior visibilidade da produção literária e artística canadense no Brasil, talvez tenha sido a atribuição do prêmio Nobel a Alice Munro, em 2013, o facilitador tanto do interesse pela literatura canadense quanto da homenagem prestada ao Canadá este ano pela Câmara Rio-Grandense do livro. Alice Munro é uma das grandes damas da literatura canadense de língua inglesa, sendo considerada a "mestra do conto contemporâneo". Tanto ela como Margaret Atwood e Margaret Laurence, traduzidas nas principais línguas do planeta, e estudadas nas grandes universidades de diferentes países, poderiam com justiça ter recebido o prêmio. A boa visibilidade da literatura canadense no exterior se deve primeiramente à divulgação das obras dessas escritoras, assim como as da romancista e poeta quebequense Anne Hébert, já falecida. Todas elas constituem-se em porta de entrada, em passagem obrigatória a todos os que querem penetrar os interiores do Novo Mundo em geral e do Canadá em particular.

\section{Da voz francesa à escritura quebequense}

Desde a chegada de Jacques Cartier ao Canadá, iniciam-se as narrativas sobre as impressões que o Novo Mundo desperta dos navegantes franceses. Podemos dizer que de 1535 a 1763 são vozes francesas que falam sobre a diversidade da região. Essa voz dos primeiros desbravadores franceses que se tornam aos poucos colonizadores vai ceder lugar à voz canadense (1763-1867), quando já são os habitantes, já nascidos no Canadá, que assumem a enunciação para narrar episódios da vida na colônia. Uma voz canadense-francesa vai preceder a literatura quebequense francófona propriamente dita que surge com a assim chamada Revolução Tranquila em 1980. Entre os enunciadores dessa voz canadense francesa está aquele que é até hoje considerado um dos maiores poetas do Quebec: Emile Nelligan.

Considerado o fundador da poesia do Quebec de cunho nacionalista, ou seja, a que assume a defesa da identidade quebequense alicerçada na língua francesa, surge, nos anos 1960, o poeta maior, Gaston Miron. É também nesta mesma fase que Anne Hébert e Gabrielle Roy começam a publicar seus romances dando origem a uma dicção feminista na literatura do Quebec, por volta dos anos antes dos 1980.

A escritora e teórica da literatura Lise Gauvin chama a atenção para o elemento que nutriu a literatura do Quebec e deu a ela o estatuto de que goza hoje em dia, o sentimento da língua: 
Compreende-se que a produção romanesca no Quebec soube tirar partido de uma certa sobreconsciência linguística e dá provas de uma palavra em liberdade que toma de empréstimo elementos tanto das tradições americanas e inglesas quanto as do romance francês. Aos códigos facilmente identificáveis sucede a introdução de efeitos de língua e de discurso. O sentimento da língua sucede a paixão de ontem. (Guavin, 1990, p. 11) ${ }^{1}$

Apropriar-se da língua francesa para torná-la maleável a ponto de exprimir a arte romanesca e poética do Quebec, inicialmente chamado de Nouvelle France, constitui-se em árduo trabalho de escritores como Gaston Miron, Gabrielle Roy, Anne Hébert e Hubert Aquin que souberam construir uma literatura que deixava de ser uma extensão da literatura francesa para se tornar literatura quebequense.

Ainda nos anos 1980, foi com Volkswagen blues (1984), de Jacques Poulin, e La Québécoite (1983), de Régine Robin, que a literatura entra plenamente em sua maturidade, pois já não tem o compromisso de falar da terra, das origens e da fundação identitária. Nesses dois romances, os personagens deambulam, entram em contato com a alteridade, indígena e mestiça no caso do romance de Poulin, e dos imigrantes judaicos no caso de Robin, abrindo as portas para o Diverso e para a Relação, para citarmos o famoso título do ensaio de Édouard Glissant: Une poétique de la Relation. Esses dois romances vão, portanto, criar um clima favorável à assim chamada literatura migrante ou transnacional que contempla dois horizontes culturais diferentes: o do país de origem do autor e o do país de acolhida, o Quebec.

Assim, os processos de imigração deram lugar a essa escrita literária de caráter transnacional no Canadá, sobretudo a partir dos anos 1980, produzida por escritores de identidade híbrida, carregada de uma herança cultural que se mescla à do país de acolhida. Nesses, a escrita literária revela o processo narrativo em que o escritor, sob a máscara de um narrador, busca unir a sua própria trajetória à de seus antepassados, o que significa tentar reconstituir a própria história e identidade, recordando o que foi recalcado, as experiências traumáticas da família, para reelaborá-las no novo contexto. Desencadeada pelo deslocamento ou pela sensibilidade para perceber o Outro, para partilhar saberes e experiências, essa produção literária adquire o caráter transcultural, através de um discurso que transita entre culturas, muitas vezes utilizando um discurso híbrido, com palavras de outros idiomas que inserem na língua predominante da escritura e revelam o compartilhamento de saberes e experiências de vida.

Tornam-se também recorrentes, na literatura contemporânea, as mudanças espaciais dos protagonistas, que, situados temporariamente em outros espaços, enfrentam a solidão, o estranhamento e encetam a busca de si mesmos, como é o caso da protagonista do romance La gare, de Sergio Kokis, narrativa de tom kafkiano, em que o protagonista desce em uma estação de trem de uma linha perdida e, quando retorna, o trem havia partido. Ele se vê, então, confinado em uma pequenina cidade, no meio de uma estepe, isolada de tudo. Sem possibilidade de retorno, ali ele vive experiências insólitas que o levam a pensar sobre a sua vida pretérita, que já não lhe servia mais, para, finalmente, experimentar um sentimento interior de libertação. Simbolicamente, o convívio com os "estranhos" habitantes da aldeia onde está exilado aguça o sentimento de reconhecimento do outro e de aceitação das diferenças, sugerindo que a chegada a um lugar como esse pode ser uma alegoria das primeiras vivências do imigrante em outro país, de cultura e língua muito diversas. Por sua vez, o protagonista de Volkswagen Blues, de Jacques Poulin, faz uma longa viagem pelos EUA em busca de um irmão, mas essa trajetória leva-o a tomar consciência dos processos de conquista do Oeste Americano, do genocídio dos indígenas, da mestiçagem na composição populacional das Américas, e, sobretudo, é uma trajetória que o impele ao autoconhecimento, provocando mudanças profundas na sua própria identidade. Conforme o escritor e ensaísta Pierre Ouellet ${ }^{2}$, na noção de migrância está a ideia de transgressão, através da qual o Eu se emancipa de sua identidade primeira:

É uma passagem ao outro, um movimento transgressivo de Um na direção do Outro, que infringe as leis do próprio, franqueia as fronteiras da propriedade ou da individualidade, para ir além, sempre, do lugar de onde veio ou de onde deriva a sua identidade, para melhor desfazer esse laço originário e renová-lo em cada novo destino, um outro devir que é também um devir outro. (OUELLET, 2005, p. 19)33.

Essa abertura favorece o desenvolvimento de uma "estesia migrante" ou "sensibilidade migratória", no dizer de Ouellet, que se revela nas "formas de percepção do

\footnotetext{
1 No original: On aura compris que la production romanesque récente au Québec a su tirer parti d'une certaine surconscience linguistique et fait la preuve d'une parole en liberté qui emprunte au moins autant aux traditions américaines et anglaises qu'á celle du roman français. Aux codes trop aisément repérables succède la mise en place d'effets de langue et de discours. Le 'sentiment de la langue' fait suite à la passion d'hier. (Gauvin, 1990, p.11)

2 Conferir no final deste número, entrevista realizada com Pierre Ouellet em novembro de 2014, por Zilá Bernd, Ana Maria Lisboa de Mello e Marie-Hélène Paret Passos, em tradução para o português por essa última entrevistadora.

3 No original: "C $\mathrm{C}$ 'est un passage à l'autre, un mouvement transgressif de l'Un vers l'Autre, qui enfreint les lois du propre, franchit les frontières de la propriété ou de 1' individualité, pour aller au-delà, toujours, du lieux d'où l'on tire son identité, pour mieux réfaire ce lien originaire et le renouer chaque fois en un nouveau destin, un autre devenir qui est auss un devenir autre" (OUELLET, 2005, p. 19)
} 
outro e de apreensão da própria alteridade", "é a mudança que $f a z$ o sujeito" e não o sujeito sendo o agente de sua transformação; a identidade está sempre em movimento interno.

Ouellet sublinha que, ao falar de literatura "migrante", não se refere apenas às obras poéticas, romanescas ou teatrais de autores nascidos em outros lugares ou descendentes de imigrantes, os quais guardam na memória e na escrita os elementos culturais da origem familiar, como é o caso, por exemplo, de Marie-Célie Agnant, em La dot de Sara, mas também da mobilidade intersubjetiva e intercultural que caracteriza também certos autores autóctones, como Nancy Huston e Yann Martel.

Essa literatura constitui-se na principal vertente no Quebec até os dias de hoje, caracterizando uma grande mobilidade cultural e possibilitando constantes passagens transculturais. Contudo, vale lembrar a fertilizadora reflexão de Pierre Ouellet para quem todos os autores são migrantes, mesmo os que nunca saíram de sua terra natal, pois através da imaginação os escritores e poetas podem eleger a sua ancestralidade intelectual em diferentes culturas e estabelecer diálogo intercultural com autores das mais diferentes geografias. E é essa feição que vem adquirindo a escritura romanesca e poética contemporânea no Quebec: a presença da diversidade cultural e da política do interculturalismo que vê com bons olhos a mestiçagem cultural, desde que os vínculos com a língua francesa sejam mantidos.

\section{A literatura de língua inglesa, com diversidade da presença ameríndia}

Até o final da Segunda Guerra, a literatura canadense não era ensinada como uma disciplina independente nas escolas e universidades canadenses, onde competia com a literatura inglesa e estadunidense, com acervos canônicos de maiores proporções. A literatura canadense de língua inglesa foi inicialmente instigada pelo desejo de ver-se como uma força que media o sentido de comunidade e de lugar, ou seja, examinava a conexão entre a escrita, a cultura e a nação, assumindo que um país sem uma literatura nacional não é um país.

A introdução de uma série de publicações intitulada New Canadian Library, colocadas em circulação por McClelland e Stewart no final dos anos 1950, permitiu aos acadêmicos do Canadá um estudo formal de escritores canadenses. Críticos ainda se inspiravam no nacionalismo romântico europeu da definição das literaturas por unidades nacionais distintas. Os tropos inescapáveis no Canadá eram natureza, o frio, os animais do norte americano e a própria noção de norte, delineadas, entre muitos outros, por Northrop Frye (The bush garden,
1971), Margaret Atwood (Survival, 1972), Glenn Gould (The idea of North, documentário radiofônico, 1967).

Na conclusão de sua história literária do Canadá, Frye observa que "Os escritores da última década, pelo menos, começaram a escrever em um mundo que é póscanadense, e é pós-americano, pós-britânico e pós tudo, exceto o mundo em si" (1995, p. 251). Um dos primeiros romances a remexer os conceitos da literatura canadense foi escrito em língua inglesa, por um judeu nascido e criado em Montreal: Beautiful losers (1966), de Leonard Cohen (hoje reconhecido cantor e compositor). As figuras principais da história passada entre Montreal e Ottawa, são um historiador, um membro do parlamento, uma santa Mohawk e a mítica esposa do historiador; a narrativa é confessional e subjetiva. A esposa indígena cometera suicídio e o amigo é um líder do movimento separatista do Quebec. O romance faz uso de muitas técnicas literárias, alusões, simbolismos, repleto de radicalismos, sexualidade e drogas, típicas dos anos 1960, e famoso por seus excessos linguísticos, técnicos e sexuais. Outros autores pioneiros da criatividade linguística e estilística são Michael Ondaatje, Timothy Findley, Nicole Brossard e Robert Kroetsch.

O pós-modernismo canadense apresenta características próprias, conforme Linda Hutcheon (com alguns livros traduzidos para o português, bastante populares entre os acadêmicos brasileiros), que se posiciona como uma mulher canadense de origem italiana, falante de inglês, mas trilíngue, um produto dos anos sessenta em termos políticos e uma acadêmica mainstream (professora de literatura comparada na Universidade de Toronto), lugar de onde lê o romance canadense contemporâneo, também sob o impacto do feminismo (1988, p. viii). Ela vê como uma boa nova a substituição da universalidade humanista como valor cultural primário para aqueles que não são anglo ou franco canadenses, ou a maioria da população do país (p. ix). Hutcheon estabelece uma distinção entre romances ainda modernistas, como The double hook (1959), de Sheila Watson e The diviners (1974), de Margaret Laurence, que ela chama de "ficções sobre a ficção", que "apesar da fragmentação e da paródia, procuram pela ordem frente aos caos moral e social" e obras pós-modernas, mais paradoxais "que ao mesmo tempo subvertem e estabelecem os poderes e convenções da arte" (p. 2). Especialmente para escritores de múltiplas culturas de origem, que ela define como "excêntricos", é possível "atacar em uma cultura da qual eles são parte, mas querem criticar" (p. 3).

Escritores franco e anglo canadenses, no entanto, conforme nos indica Hutcheon, precisavam promover a desconstrução do passado colonial, Thomas Findley (1977), em The wars, do imperialismo, George Bowering, em Burning water (1980), do picaresco, Anita Van Herk, 
em No fixed address (1986), do Külstlerroman, Alice Munro, em Lives of girls and women (1971), a lenda do Graal, Audrey Thomas, em Mrs. Blood (1992), ou o faroeste, nos romances de Kroetch (HUTCHEON, 1988, p. 6). Ela denomina estas obras "metaficção historiográfica", ficção "intensamente autorreflexiva" ancorada em realidades históricas, sócias e políticas (p. 13, 61). Hutcheon destaca ainda as escritoras canadenses, como é imprescindível em um país cuja literatura é identificada no mundo através de nomes como Margaret Atwood, Nancy Huston e Alice Munro. Entre as obras que ela destaca são Intertidal life (1984), de Audrey Thomas, uma "paródia que problematiza o gênero romance e as questões de gênero ao mesmo tempo" (p. 111). O romance, ambientado na costa oeste do Canadá, aborda os temas preferidos de Thomas, as inquietantes relações entre homens e mulheres, mulheres e mulheres, mulheres e crianças, onde há muitas perguntas e nenhuma resposta. Mais radical em sua forma, The biggest modern woman in the world (2007), de Susan Swann, é a biografia ficcional de uma gigante vitoriana, nascida na Nova Escócia em 1846, narrada em primeira pessoa, que apesar de fantástica, é a história de todas as mulheres. O romance perpassa com muito humor questões de gênero, arte, sexualidade e nacionalidade.

Mas muitas outras autoras merecem destaque e Carol Shields, Marian Engel, Sandra Birdsell, Ethel Wilson, Evelyn Lau, Elizabeth Hay, Ann-Marie MacDonald formam uma modesta lista de boa literatura a explorar a vida nas várias províncias, o passado e o presente da vida no Canadá.

O pós-colonialismo dá continuidade não só à desconstrução do passado, como abre espaço para vozes até então marginais, como as que examinam a presença dos não brancos, dos sujeitos diásporicos, dos aborígines, ao mesmo tempo "insiders/outsiders" (BANNERJEE, 2004, p. 289): Jeanette Armstrong, Thomas King, Lee Maracle, Marie Batiste, Himani Bannerji, Arum Mukerjee, Rinaldo Walcott, Dionne Brand, Joy Kogawa, Paul Yee, Marilú Mallet.

Três autores premiados, que representam a escrita marcada pela racialidade e, ao mesmo tempo, apresentam atos de resistência e propostas críticas de exercício da diferença, são Jeanette Armstrong, em Slash (1985), Roy Miki, em Surrender (2001), e Dionne Brand em What we all long for (2005). Slash recupera a história do Movimento Indígena de Protesto (AIM, American Indian Movement) através da personagem Okanogan, orgulhoso de sua herança cultural (como a autora), que depois de experimentar as escolas internas assimilacionistas e escolas públicas racistas, torna-se um ativista do Movimento Indígena. Leitores ocidentais tiveram dificuldade de entender a obra devido a seu caráter híbrido e pouco familiar, que não prioriza o discurso ou a escrita e é original em sua proposta estética e didática de descentramento cultural. $\mathrm{O}$ estranhamento provém do fato de a obra forçar o leitor a confrontar-se com o próprio racismo e arrogância cultural e abrir-se para aprender algo que nunca aprendera a ver ou ouvir. Roy Miki, poeta de uma segunda geração de japoneses de Winnipeg, recebeu o Governor General's Awards por Surrender, poemas que narram a internação dos japoneses durante a Segunda Guerra, transformando pacatos cidadãos canadenses em inimigos de forma friamente burocrática, destituindo-os de suas propriedades e de sua dignidade. Mas Miki não dramatiza este vergonhoso momento da história norte americana e da geração de seus pais e prefere basear-se em evidências documentais que emprestam uma presença indiscutível dos fatos a seu trabalho. Sua escolha de poemas polifônicos, vários textos apresentados simultaneamente em páginas opostas do livro, estão entre os mais interessantes da obra. Nascida em Guayaguayare, na República de Trinidade e Tobago, Brand também recebeu um Governor General's Award de Poesia. What we all long for é a justaposição da história de quatro personagens vivendo em Toronto: Tuyen, uma artista lésbica, filha de Vietnamitas e irmã de um menino perdido durante a fuga do país nos anos 1970, uma quinta personagem quase fantasma, que sobrevive na Tailândia; Clara, uma courrier birracial que precisa lidar com o suicídio da mãe e a delinquência do irmão; $\mathrm{Oku}$, um poeta apaixonado por jazz que abandonou a universidade sem o conhecimento de seus pais jamaicanos e Jackie, uma linda jamaicana que só namora homens brancos e está distanciada de seus pais socialmente decadentes. O romance é considerado um retrato da Toronto contemporânea, multirracial e multivocal e o trio de obras mencionadas pode ser considerado um exemplo das infinitas possibilidades da literatura de língua inglesa no Canadá contemporâneo.

No contexto do bilinguismo, assim como nas definições de literatura pós-colonial, são excluídos os povos indígenas canadenses, cuja história tem dezenas de milhares de anos mais do que o processo colonial nas Américas e muitas nações com suas línguas e culturas ativas. Autores de várias etnias conseguiram penetrar o cânone canadense, mesmo escrevendo em inglês, através de elementos de suas culturas, como os ritmos da oralidade que perpassam as narrativas, algumas obras em línguas indígenas, que reforçam o fato de continuarem vivas e faladas até hoje, e a reintrodução da figura do trickster, um ser mitológico com o poder de criar mundos e transformar mundos e de transformar-se nos mais diversos seres, são algumas das estratégias de sobrevivência e de resistência refletidas na literatura das Primeiras Nações canadenses. 


\section{Conclusões}

Como aponta Carmine Starnino, referindo-se à poesia canadense, "a tradição [para eles] não é velha ou outra, mas está ao alcance da mão, simultânea e viva", para ser "absorvida, redesdobrada e renovada". Para Starnino "a liberdade de não ter que escrever dentro da tradição literária, diferentemente dos estadunidenses, possibilita que fiquem fora dela ao nela entrar", o que constituiria uma "dupla voz subversiva", uma "dupla atitude de herdeiro e progenitor", e geradora de uma identidade ao mesmo tempo "fixa e fluída" (New Canadian Tricks, artigo inédito). Hutcheon descreve essa dualidade como "uma voz dupla, com a língua bifurcada da ironia", que permite "dirigir-se e ao mesmo tempo confrontar o discurso "oficial", "trabalhar dentro de uma tradição dominante, mas conseguir mudá-la, sem ser totalmente cooptada por ela". A estratégia "seria não só uma estratégia de sobrevivência, como uma espécie de celebração para os escritores canadenses" (HUTCHEON, 1991, p. 1-4) que através dela abordam as questões de raça e etnicidade, os desafios feministas e póscoloniais, e até os visuais, na fotografia canadense, outra desconhecida entre nós. George Bowering diz ter a impressão de que "os canadenses escrevem livros uns para os outros" (BOWERING, 1988, p. 2), ironizando sobre certa obsessão com as dualidades e multiplicidades do país.

Quem sabe precisamos conhecer melhor o Canadá, este país com alto índice de desenvolvimento humano, plural e complexo em sua história e sua geografia para desenvolver maior interesse por sua literatura igualmente múltipla e de alto nível. Apesar da presença ativa da ABECAN até 2012 e da revista Interfaces Brasil Canadá, de dissertações de mestrado e teses de doutorado sobre a literatura canadense, apresentadas em diferentes universidades brasileiras, a circulação da literatura canadense no Brasil ainda é muito reduzida, sendo o fator principal dessa pouca penetração a ausência significativa de traduções e de edições feitas por editoras influentes com boa distribuição.

Por isso foi muito importante para uma maior visibilidade da literatura canadense no Brasil a homenagem que a $60^{\text {a }}$ Feira do Livro de Porto Alegre fez, escolhendo o Canadá como país homenageado em 2014. Vários escritores se apresentaram pessoalmente ao público sul-rio-grandense, entre os quais o premiado Pierre Ouellet, Claire Varin, Isabel Vincent, Susanne Lebeau, Plilippe Ducros, Myriane El Yamani, Richard Scrimger e Ludmila Zeman, e trouxeram até nós o romance, o ensaio crítico, o jornalismo investigativo, o teatro, a contação de histórias, a literatura infantil, a ilustração canadenses e o intercâmbio com a literatura brasileira.
Vários editores participaram da comitiva canadense para estabelecer contados com os editores brasileiros, com vistas a traduções em língua portuguesa, já que a tradução é a mediadora cultural por excelência visa contribuir para ampliar os leitores da literatura canadense cuja riqueza está em sua característica bilíngue que nos põe em contato com um país imenso, multicultural e multiétnico através de duas línguas: o inglês e o francês que apresentam o país de duas perspectivas diferentes. Enquanto a literatura em língua inglesa convida os leitores a mergulhar em um universo multicultural e em suas passagens transnacionais devido à multiplicidade de culturas em presença, a de língua francesa ou quebequense leva os leitores a identificarem as políticas do interculturalismo, a acompanhar o trabalho dos escritores ditos migrantes que compõem seus textos com os fragmentos memoriais das culturas de origem tecendo-os com elementos da cultura quebequense no anseio de construir redes de pertença nacionais e interamericanas.

\section{Referências}

BANNERJI, Himani. Geography lessons: on being an insider/ outsider to the Canadian nation. In: SUGARS, Cynthia (Ed.). Unhomely states: theorizing Englsish-Canadian postcolonialism. Toronto: Broadview Press, 2004.

BERND, Zilá; MELANÇON, Joseph (Orgs.). Vozes do Quebec - antologia. Porto Alegre: Editora da UFRGS, 1991.

BOWERING, George. A great northward darkness. Imaginary hand. Edmonton: Imaginary Press, 1988.

FRÈDÉRIC, Madeleine. Polyptyque québécois: découvrir le Roman contemporain (1945-2001). Bruxelas: Peter Lang, 2005 .

FRYE, Northrop. Conclusion to a Literary history of Canada. The bush garden - Essays on the Canadian imagination. Concord, Ontario: Anansi, 1995, p. 215-253.

GAUVIN, Lise. L'écrivain et la langue. Europe - revue littéraire mensuelle: Littérature nouvelle du Quebec, n. 731, mar. 1990.

HUTCHEON, Linda. The Canadian postmodern. A study of contemporary English-Canadian fiction. Toronto, New York, Oxford: University of Oxford Press, 1988.

HUTCHEON, Linda. Splitting images: Contemporary Canadian ironies. Toronto, Oxford, New York: Oxford Univeristy Press, 1991.

OUELLET, Pierre. L'esprit migrateur. Montréal: VLB, 2005. STARNINO, Carmine. New Canadian Tricks, 2014. (inédito)

Recebido: 15 de outubro de 2014 Aprovado: 07 de janeiro de 2015 Contatos: zilabster@gmail.com ana.lisboa@pucrs.br eloinaprati@gmail.com 